\title{
Customisation and Fashion Logistics Effects of Flat Knitted Fashion Products using Complete Garment Technology SAMAND’ OR - A Case Study
}

Joel Peterson*

The Swedish School of Textiles, University of Borås, Skaraborgsvägen Borås, Sweden

\section{Introduction}

One of the identified problems in the textile and fashion business of today is that much of the garments that are bought must be sold in the stores at discounted prices, which results in poor results such as, low sell-through percentage, stock-turnover and lost-sales. The study in this article suggests that a combination of mass customisation (MC), complete garment knitting technology and supply chain management can show an alternative way to overcome this drawback for customised knitted products. Fernie and Azuma [1] state that one direction for the fashion industry may be to reconsider the option of more domestic manufacturing in the future. For many years the trend in the textile and fashion business has been to source production in low-income countries in order to maximise gross profit margins for the company. Can domestic production combined with $\mathrm{MC}$ be an option for the future to be successful in fashion retailing?

Supply Chain Management (SCM) is now seen as a broader concept of manufacturing and retailing than earlier views that limited it to individual companies. In a chain for textiles and apparel, all parts must be synchronised and able to adapt to demands on the market. This is especially crucial for the types of products that fashion represents shown in the study of Bruce et al. [2]. Nowadays research shows that SCM focuses on relationships between those in the supply chain $[3,4]$. SCM takes a wide view of configurations, which Gattorna [5] defines as "any combination of processes, functions, activities, relationships and pathways along which products, services, information and financial transactions move in and between enterprises, in both directions".

The supply chain needs to be time-based, customer-oriented, and agile in response to changes in demand [6]. A study of Finnish retailing companies' shows that the financial performance of traditional retailers with up-front buying is far poorer compared to retailers with in-season replenishment purchasing [7]. Time is an important factor from demand to fulfilment, that is, from the moment customer request is identified until the customer buys the product. Gattorna stresses the importance of having the definition embrace everyone in the company for the supply chain to work [5]. This is consistent, and in line with the results Bruce et al. [2] presented in 2004 that a supply chain must be align and responsive.

For this reason, it can be an advantage to collaborate in the supply chain and to bring products to market as quickly as possible or retailers may be left holding unsaleable merchandise because items have gone out of fashion. The ideal would be to have an efficient system that could deliver garments in one or two days, or even in hours, as they are sold. Such logistics activities require different kinds of sourcing, production, and inventory management than are currently being used. A company built on mass customisation can be an example of such a concept.

The production of knitted fashion products has developed considerably since the 1970 s due to improvements in electronics, computer engineering and availability of new fibres [8]. Two stages preceded complete garment technology. Cut \& sew is a common method of making flat knitted garments. Rectangular panels for the front, back, and sleeves are knitted, then cut into shape, and finally joined together by the sewing process. Fully-fashioned or shaped knitting is a method of production in which the front, back, and sleeves are knitted in approximately the right shape directly in the knitting machine, but some additional cutting may be needed [9]. After the knitting process, the parts are sewn together to form a garment.

Complete garment technology (seamless garment technology or WholeGarment.) was introduced on V-bed flat knitting machines in 1995 , having evolved from developments in the 1980s. Since then, the technology has been considered an innovative process and is steadily increasing in use around the world [9]. In this type of production, the entire garment is ready-made directly in the flat knitting machine. The different parts of the garment are produced in the right shape and knitted together with the trimmings, pockets, and other accessories. This technology makes it possible to eliminate cutting and sewing operations and produce 'on-demand' knitting, which can shorten lead times considerably [10].

In 1987 Stan Davis, a visionary business thinker and consultant coined the term mass customisation (MC) for the first time. He described it as a system in which "the same large number of customers can be reached, as in mass markets of the industrial economy, but simultaneously can be treated individually, as in the era of customised markets in pre-industrial economies" [11]. This was developed further by Pine [12], who defined it as a concept that provides such variety and individual customisation that almost everyone can find what they want at prices comparable to mass-produced products. MC involves all aspects of development, manufacturing, sales, and delivery of the product $[13,14]$. It is a concept that comprises the whole chain from the designer's sketch to the final product received by the customer.

MC allows buyers to modify products according to their taste and requirements. It exists today in a variety of areas including automobiles, furniture, food, and clothing. One advantage for the retailer is that the product can typically be sold before the manufacturing takes place. Since the customer has already purchased the product, the risk for unsold goods is lower. Customers are not always satisfied with the products they have customised and bought. For such cases it is important to have a return policy which allows returning with full refund [15].

*Corresponding author: Joel Peterson, The Swedish School of Textiles, University of Borås, Skaraborgsvägen 3, S-50190 Borås, Sweden, Tel: +46-33-4354171; Fax: +46-33-6879-4354009; E-mail: joel.peterson@hb.se

Received December 10, 2015; Accepted January 06, 2016; Published January 15,2016

Citation: Peterson J (2016) Customisation and Fashion Logistics Effects of Flat Knitted Fashion Products using Complete Garment Technology SAMAND' OR - A Case Study. J Textile Sci Eng 6: 232. doi:10.4172/2165-8064.1000232

Copyright: (c 2016 Peterson J. This is an open-access article distributed under the terms of the Creative Commons Attribution License, which permits unrestricted use, distribution, and reproduction in any medium, provided the original author and source are credited. 
While MC may not replace mass production of clothing, it may be a solution for certain products and niche markets. In some ways the MC of clothing may be seen as a step back in time. We are reminded of the crafts era, when clothing was made to order as needed and produced near-by. Now this is being done again, but with modern technology-a return to clothing designed and manufactured in collaboration with the wearer. Here complete garment technology opens up new perspectives with its reduction of processes that allow a rapid response to customer demand, while the possibility of $\mathrm{MC}$ serves each customer individually. Fashion logistics, MC, and complete garment technology form an effective partnership. These three concepts are the focus of this paper. They are relatively new and, while they have been considered separately, they have rarely or not at all been examined in combination.

The principal objective of the present study is to examine the use of complete garment flat knitting technology for the production of customised knitted garments. It is hoped that this will contribute to the industry discussion of how complete garment knitting technology can be applied in the MC of fashion products. This study poses the following research questions:

Research question one (RQ1): How can complete garment knitting technology be applied in a retail concept for customised garments?

Research question two (RQ2): "What impacts can be expected on retail performance effects, such as: sell-through factor, lost sales and stock turn by combining complete garment technology and MC?"

The answer is pursued by a literature review and a case study of the fashion company SAMAND' OR.

\section{Methodology}

In order to show how knitting technology in general and complete garment knitting technology in particular can be used for the mass customisation of flat-knitted products, this article uses an inductive approach based on a case study involving both company visits and interviews of personnel [16]. For the study of SAMAND' OR:s customisation and production concept, information and data was collected through company visits and oral interviews with staff in the store. The people interviewed were two of the shop personnel and two of the representatives from the management of the parent company SHIMA SEIKI. The interview method used was the semi-structured interview, a method of research used in the social sciences described by Bryman [17]. Each interview lasted between half an hour to one hour and the answers of the questions were noted on a form and afterwards divided into two groups, depending on whether the question was of a qualitative or quantitative nature.

The quantitative results regarding sell-through factor, lost sales and stock-turn were analysed by the data triangulation method [18]. The data were triangulated with the results from two other studies on mass customisation of knitted products [19,20].

The qualitative data in this study seeks to identify critical factors of success in fashion retailing for knitted products. A SWOT analysis is a structured method used to evaluate the Strengths, Weaknesses, Opportunities and Threats for a project, business idea or a company. Advantages and disadvantages are studied, analysed and noted in the four squares of a SWOT matrix $[21,22]$. The in-data for the SWOT analysis in this study was collected during two visits to the SAMAND'OR store in Tokyo during 2014. Information was also collected by the participant-observation-method were a fictitious customer's garment were designed, and the simulated customisation process studied from beginning to end. Two garments in complete garment knitting were simulated in this fictitious customer customisation process.

\section{The research gap, validity and confidentiality of the study}

The research gap was identified by a literature review. Complete garment knitting technology is a niche area in textile technology. It is difficult to find research literature on the subject, especially in combination with $\mathrm{MC}$ and fashion logistics. The possibilities of using complete garment machines for the production of mass customised products are discussed by Choi and Powell [8] and Choi [9]. There are a number of articles and some books describing and discussing complete garment technique, all of which presents the history, technical aspects and an overview of the subject $[8-10,23]$. However, none of these sources provide a deep picture of the complete garment technique in combination with $\mathrm{MC}$ of fashion garments.

While there is some research on the significance of fashion logistics and agile supply chains $[7,24,25]$, little has been written about the fashion logistics effects of complete garment technology combined with MC.

However, if we are to argue that MC provides a complement to mass production of knitted garments, it remains a matter of concern that there are no research-based studies for this type of co-design in combination with complete garment technology. This study will suggest two research questions which need to be addressed when considering the combination of these three areas and the technical aspects for development of such a concept.

One factor to consider in evaluating the results of this study is that only store employees and representatives from SHIMA SEIKI were interviewed, no customers. This should be taken into account when the validity of the study is assessed. The presentation of detailed data in the results section is limited due to confidentiality especially regarding SAMAND' OR:s fashion logistics effects and economic performance.

\section{Definitions and success factors in fashion logistics}

The textile and fashion industry is often characterised by the uncertainty of its market. Logistics for fashion products are marked by a climate of uncertainty due to rapid changes in trends and fluctuating customer demand. For this reason, it can be an advantage to bring products to market as quickly as possible or retailers may be left holding unsalable merchandise because items have gone out of fashion. The rent for an upscale clothing store in a good location is very high, so it is essential to carry the correct level of inventory. Such a retail shop is too expensive to use as a warehouse; on the other hand, too little stock will result in customers not finding what they want. The ideal would be to have an efficient system that could restock garments in one or two days, or even in hours, as they are sold. Such logistic activities require different kinds of sourcing, production, and inventory management than are currently being used.

A supply chain and logistics system must be integrated in order to reduce lead time. This imposes special requirements on the companies in the supply chain. It is an accepted fact in the industry that the demand for fashion products is difficult to forecast. Fashion markets have been characterised as open systems that are often chaotic [24]. For many years the trend in the textile and fashion business has been to source production in low-income countries in order to maximise gross profit margins for the company. This philosophy can have a negative impact on revenue because of the lead times necessitated by long-range forecasts ahead of sales campaigns. The danger of sourcing to such countries months before the season is an excess of inventory, a greater 
number of products that must eventually be sold at discounted prices, the risk that customers cannot find what they want in the shop, and ultimately a loss of profit [8].

Christopher and Peck [26] list three dimensions of time-based consumption: time to market, or how long it takes a business to recognise a market opportunity, translate it into a product or service, and bring it to the market; time to serve, or how long it takes to secure a customer's order and deliver or install the product to the customer's satisfaction; and time to react, or how long it takes to adjust the output of the business in response to volatile demand, that is, how quickly the supply "tap" can be turned on and off.

In this study demand fulfilment time is defined as the time it takes from when customer demand is identified to when the product is delivered to the customer. It may be subdivided into design time, production time, and transportation time. These consist of value-added and non-value added time. Value-added time is an interval in which a process such as knitting, sewing, or dyeing a garment takes place that adds something of value to the product. Non-value added time is a period of waiting between value-added processes.

It is of paramount importance to keep time to market as short as possible if one is to fulfil customer demand [27]. An example of this may be seen in a supply chain flowchart for a knitwear garment that identifies processing and inventory time and calculates value-added and non-value-added activities (Figure 1). Processing time (valueadded activities) is shown to be 57 days, and waiting time or inventory time (non-value adding activities) is calculated at 110 days. The total lead time is thus 167 days [28].

In the 1980s the American consulting firm Kurt Salmon conducted a supply chain analysis of the textile and apparel industry in the US that revealed the average lead time from raw material to consumer was 66 weeks [25]. However, only 11 weeks were associated with manufacturing processes themselves, while nearly 40 weeks were consumed by waiting time in warehouses or in transit. The remaining 15 weeks consisted of shelf time in the store before the garments were purchased. The analysis revealed that instead of trying to minimise costs independent of one other in the different parts of the supply chain (fibre, textile manufacturing, apparel wholesaler, and retail), costs increased. Many customers could not find the style, colour, or size they sought. The store's inventory was based on forecasts made far ahead of season, so when the products became available in the shop, they were already out of fashion.

Four critical success factors can be identified for sourcing of seasonal products with a fashion content: forecast accuracy, process lead time, off-shore/local sourcing mix, and up-front/replenishment buying mix [29]. "High gross margins and customer service levels with as little inventory as possible" are essential for profitable retail fashion companies, according to the article by Matilla, King and Ojala [7]. King and Hunter, [30] propose retail performance ratios that can measure the success of sourcing and how well the range of products offered by a store meets customer demand.

Three fashion logistics key factors important in retailing are focused on in this study. The sell-through factor is defined as the percentage of products sold at full price in the store and an important factor for a high sell-through factor is the lead time, demand fulfillment time, from design to the point when the customer buys the garment. This time should be as short as possible [7,30]. Lost sales refer to how many customers visit a store but do not purchase anything. It is important to keep lost sales as low as possible in order to not loose profit [29].

The ratio of inventory compared to sales is a measure of a company's stock turn. The purpose of this study was to analyse the fashion logistic effects of combining complete garment technology and MC, rather than calculating absolute values of stock turn.

Fiore et al. [31] identify the two essential elements in the MC of apparel: 1) co-design for a unique product, and 2) body scanning for a better fit. In co-design, the customer (generally with the aid of CAD technology or professional assistance) assembles an individualised product from a company's offerings by choosing style, fabric, colour palette, pattern, and size. In order to get a customised garment with a

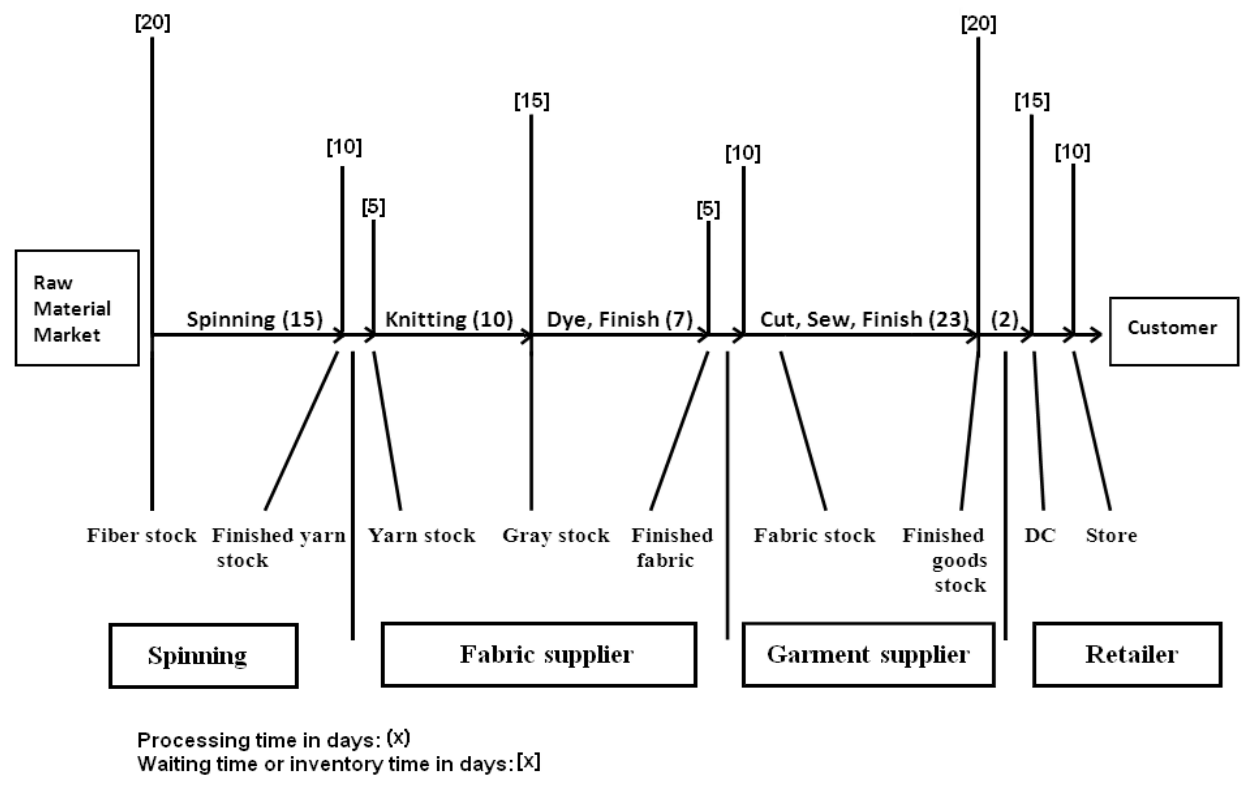

Figure 1: Length of supply chain in knitwear garment supply pipeline [28]. 
perfect fit, the client's measurements can be taken by body scanning, although some customers do not want to be scanned.

At the SAMAND' OR store in Tokyo, Japan, the co-design process can be observed as the kind of tailored customisation described by Lampel and Mintzberg [32] and Gilmore and Pine [33]. Customers browse the store for a garment they like and it becomes the starting point of the product's design. The interaction between client and store personnel is crucial as the customer proceeds to customise an item. One of the impediments to applying the $\mathrm{MC}$ concept for manufacturing flat knitted products by complete garment technology has been the codesign process itself. It continues to require manual interaction between the customer and a shop employee throughout the customisation process. This article investigates expanding opportunities for $\mathrm{MC}$ and ways in which manual and digital co-design can be integrated with complete garment technology.

\section{Production methods for flat knitted fashion garments}

Flat knitting machines traditionally produce knit panels with coarse structures, a fixed edge, a welt at the bottom of the panel, and patterns such as rib, Milano rib, jacquard, stripes, or cables across the panel. The production from yarn to ready-made garment can be done in several ways with this technology, depending on method and type of machinery used. The process consists of several operations, as shown in Figure 2.

The knitting process begins as yarn-on-yarn cones are knitted to panels in the flat knitting machine. The panels are often steamed in a finishing stage after knitting. Then the panels are cut to size and shape, and sewn together into a garment. To achieve the desired level of quality, the garment may be finished by steaming or washing. Traditionally, the manufacturing process subjects coarse flat knitted garments to several time-consuming operations after knitting. Flat knitted garments can be manufactured by four distinct production methods: 1) cut and sew, 2) fully-fashioned, 3) integral knitting, and 4) complete garment. Cut \& sew is a common method of producing flat knitted garments. Panels for front, back, and sleeves are knitted in a rectangular form and then cut into shape (Figure 3), [8,34]. The panels are then sewn together, and separately knitted trimmings and pockets are attached to complete the garment. Both cutting and sewing are post-knit processes that take place away from the knitting machine. Up to $40 \%$ of the original fabric may be wasted as cut-loss in cut and sew [3].

Fully-fashioned, or shaped knitting, is a method of production in which the front, back, and sleeve pieces are knitted in the right shape directly in the knitting machine $[8,9]$. The cutting process is either minimal or eliminated entirely, but some post-knit cutting may still be necessary. Trimmings and pockets are knitted separately and sewn together with the rest of the knitted elements to complete the garment. The benefit of this production method is that cutting is generally avoided making material consumption and labour costs lower than the cut and sew production method showed in Figure 3

\section{Complete garment}

In complete garment production the entire garment is ready-made directly in the flat knitting machine. The different parts of the garment are knitted in the right shape and knitted together with the trimmings, pockets, and other decorative elements in place as presented in Figure 4 [9]. The advantage of this technique is no waste of material (cutloss) and no expensive post-knit operations (sewing or cutting) [10]. Depending on the style of the garment, some minor cutting and sewing of labels or trim may still be necessary. In addition, while panels sewn together using other manufacturing techniques run the risk of having variations in colour shades between the panels because they were knitted with yarn from various dye lots, in complete garment technique all the yarn comes from the same cones, enabling higher quality and reducing problems of colour mismatch. With seamless technology, the garment can be made to fit perfectly and be comfortable to wear. In summary, manufacturing processes are reduced and knitting is done on-demand, which can shorten production lead time considerably [10].

\section{From craft to customisation in the fashion industry}

Before the industrial revolution, which began in the $18^{\text {th }}$ century, manufacturing was largely a craft process. A product was custom made to fulfil the requirements of an individual person. It was often expensive and therefore available only to those who could afford it [35]. With the industrial revolution and the era of mass production, more goods could be obtained by more people. Today MC has emerged as a combination of craft and mass production. The textile and fashion industry was one of the first to adopt this concept.

Tseng and Piller [36] cite three aspects of apparel that must be capable of modification to be successful in an MC scheme: fit (size and shape), function (adaptability to use), and design (taste and form). Products whose physical dimensions and functional properties can be changed are more suitable for customisation then articles in which only colour and pattern can be varied. Above all, a garment must fit a customer well.

In order to produce a customised garment with a perfect fit, the client's measurements must be determined accurately. At a retail

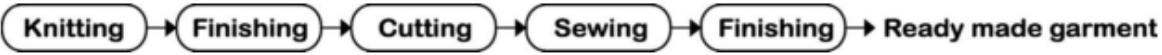

Figure 2: Production process for flat knitted garments.

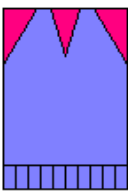

Front pane

Waste (cut-loss)

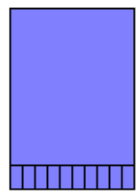

Back pane

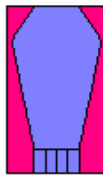

Sleeve

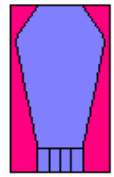

Sleeve

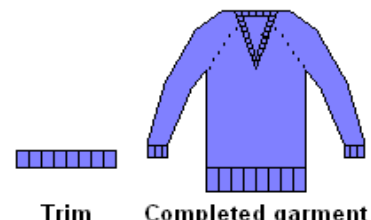

Trim

Completed garment

Figure 3: Cut and sew production method. 


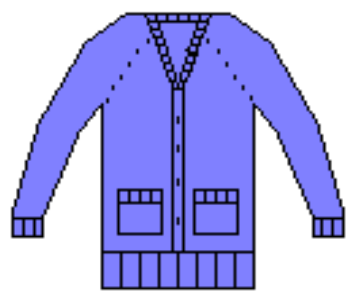

\section{Complete garment}

Figure 4: Complete garment production method

location shop personnel can take customer measurements by hand, body scanning, or video camera [37]. However, on-line shopping presents other challenges.

Body scanning has often been mentioned as a solution to the problem of perfect fit. Its disadvantages are three-fold: 1) an investment in specialised equipment is required, 2) not all people wish to be scanned, and 3) certain types of clothing require taking a customer's measurements manually. However, the impact can also be that some customers find body scanning exciting and like the experience of the process and that they also like to get the advantage of having accurate measurements. A manual procedure also enables a dialogue between the purchaser and the salesperson about the preferred fit of the garment, i.e., tight or roomy, an aspect often overlooked in promoting body scanning. On the negative side, taking measurements manually can be more time consuming and may raise issues of personal privacy. Catering to individual customer sizes becomes an even bigger problem in e-commerce.

For a business to be engaged in the sale of mass-customised products, the traditional structure of development, production, and distribution needs to be reformulated from a linear to a concurrent or parallel process $[38,39]$. Closing the sale with a customer becomes one of the initial steps in a retail transaction, rather than the final one. From that point, streamlining time-consuming manufacturing operations after the point-of-sale is the key to shortening delivery time. Situating the manufacturing process after the point-of sale eliminates or reduces a company's inventory of ready-made garments and may increase its stock-turn percentage.

\section{SAMAND' OR - A Case Study}

In 1995, the Japanese manufacturer SHIMA SEIKI introduced the first complete garment knitting machine capable of producing a readymade flat-knitted garment on the machine. The company launched the complete garment concept under the name WholeGarment. In the same year, Wajima Kohsan Ltd. opened the first Factory Boutique in Wakayama, Japan as a retail store specialising in on-demand production of customised knitted garments. SAMAND' OR is a business concept launched by SHIMA SEIKI in 2012 that combines knitting technology and mass customisation (Figure 5). The store is located at the fashionable department store Takashimaya located in the business district of Nihombashi in Tokyo.

The shop welcomes a customer to enter the showroom, design and customise a flat-knitted garment. In the boutique, the client has the opportunity of examining fashion magazines, swatches of knitted fabric, colour charts and garment samples for ideas while designing their own custom garment. A photograph is taken in a small photo studio and then the customer offers the opportunity to see her dressed in garment styles that are available for in the store. In the computer it is also possible to change yarn colour, sleeve lengths, neck-style and background view. A selection of garments in various sizes may be tried on to assure a perfect fit. In creating a personal item, the client is guided through the customisation process by a shop assistant skilled in clothing design. The SAMAND' OR concept offers garments in fully-fashioned and complete garment manufacturing methods with different options in each technology. Customisation may range from small changes or adjustments of a sample garment to a more complicated full design process incorporating personal choices from start to finish. The path from entering the retail shop until the custom designed garment is purchased, manufactured, and delivered (Table 1).

An important part of the customisation process is the personal fit of the garment. For this reason, measurements are carefully taken by trained personnel. After the customisation has been completed, the customer is still free to decide whether or not to purchase the garment. If the self-designed garment should be bought payment must be made in the store immediately. Then the specific order-form with all product data is e-mailed to the production facilities in Wakayama. The order-form contains information about: garment size, material, pattern, neck type, attachments, delivery address and desired delivery time. The garment is manufactured and delivered by post to the customers address. It is also possible for the customer to pick up the finished garment in the store in Tokyo if desired. SAMAND' OR has the customer's measurements and it enables ordering of new garments in future. Some clients, but not so many have done this, but according to interviews with the staff this is an opportunity for the company and can be developed more in the future.

From the perspective of the customer, there are clear differences between fully-fashioned garments on one hand and complete garment products on the other. The first one gives more customisation possibilities. The complete garment alternative, however, is made without cutting and sewing, i.e., the entire garment is created in one continuous operation on the knitting machine. This type of

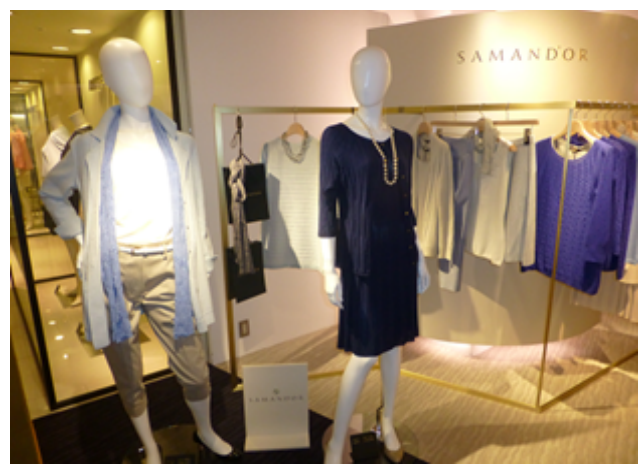

Figure 5: SAMAND' OR fashion store in Tokyo.

\begin{tabular}{|c|}
\hline The SAMAND' OR customisation concept \\
\hline Customer enters the store \\
Browsing in the store \\
\hline Design and customisation of the garment \\
\hline Point of sale \\
\hline Placing order and prepaying for purchase \\
\hline Manufacturing of customised garment \\
\hline Delivery of the garment by post \\
\hline
\end{tabular}

Table 1: The SAMAND' OR customisation concept. 
manufacturing results in a seamless product which, as suggested above, has a more perfect fit and drape than is possible for sewn products.

\section{Results}

The quantitative data in this case study indicates that some important factors for success in SAMAND' OR are more significant than for traditional fashion retailing companies. The data was collected by interviews and analysed by the data triangulation method and it proved to be consistent with previous studies in the area by Peterson, Mattila [19] and Larsson et al. [20]. The data presented in Table 2 shows that the sell-through factor is almost $90-100 \%$, compared to the average of $65-70 \%$ in ordinary fashion retailing [9].

For the SWOT analysis of SAMAND' OR's customisation and production concept the shop in Takashimaya department store in Tokyo was visited and shop personnel were interviewed along with the representatives from SHIMA SEIKI. The result of the SWOT analyses is shown in Table 3. The SWOT analysis indicates strengths such as a high sell-through factor, no carrying of an inventory of ready-made garments and a positive shopping experience for the customer. Are we to conclude that the SAMAND'OR concept is successful? Thus far, it seems to have served to demonstrate how WholeGarment technology can be used for mass customisation in the future. Some aspects of the concept must be improved or altered if the idea is to be spread to other textile or retailing companies.

There are certainly business advantages in having the customer pay for the product before it is manufactured, and this may become one way for fashion retailing companies to compete for market share in the future. It is very expensive to carry an inventory of products that may be out of style by the time a customer comes into the shop. SAMAND' OR needs to develop its co-design system to the point that customers do more of the customisation themselves. The current system, where one or two staff members devote their full attention to the customer during the co-design process, provides very good service for the customer. However, attending to one customer at a time is costly for the company.

\begin{tabular}{|c|c|c|}
\hline Success factors & Ordinary fashion retailing & SAMAND' OR \\
\hline Sell-through factor & $65-70 \%$ & $90-100 \%$ \\
\hline Lost sales & $20 \%$ & $5 \%$ \\
\hline Stock turn & $2-5$ times/year & High \\
\hline
\end{tabular}

Table 2: Expected impacts of critical factors for success for the company SAMAND' OR.

\begin{tabular}{|c|c|}
\hline Strengths & Weaknesses \\
\hline No inventory of ready-made garments & $\begin{array}{l}\text { Customers cannot take product home } \\
\text { with them }\end{array}$ \\
\hline No seasonal sales & $\begin{array}{l}\text { Risk of long queue of customers in the } \\
\text { shop }\end{array}$ \\
\hline $\begin{array}{l}\text { Positive shopping experience for the } \\
\text { customer }\end{array}$ & $\begin{array}{l}\text { Limited retailing experience for the } \\
\text { company }\end{array}$ \\
\hline High sell-through factor & Time consuming co-design process \\
\hline Low lost sales & Little re-use of customised information \\
\hline Opportunities & Threats \\
\hline To develop the co-design process & $\begin{array}{l}\text { Customers must wait to receive garment } \\
\text { purchased }\end{array}$ \\
\hline Large potential markets & Time consuming co-design process \\
\hline Sell know-how to other retailers & Limited interest among customers \\
\hline Internet sale & \\
\hline
\end{tabular}

Table 3: SWOT analysis of the business concept of SAMAND' OR.
The analysis suggested that internet sales may present an opportunity for the future. With an efficient co-design system on a company's web page, more customers could be reached at the same time. At that point, the problem of getting accurate customer measurements will present itself. SAMAND' OR shares this dilemma with other companies who sell customised fashion garments over the internet today. One solution may be to let the customer enter their own measurements directly into the co-design system as many companies already do. However, it may be difficult to do this correctly and some people may resist the process altogether. The result of the analysis shows that there are two main tracks that SAMAND' OR must concentrate on to improve their business concept. The first already comprises one of the company's strengths, i.e., products being manufactured with complete garment technology must continue to be adopted for mass customisation. The second is the development of the customisation concept itself. SAMAND' OR might benefit from studying other mass customisation schemes such as TAILOR STORE Company and NIKEiD and turn to experts in the field of mass customisation to help refine their concept and better adopt it to their knitted products so that their business will succeed. This can be done by limiting the available options and, thereby, avoiding mass confusion which means that the customer can be distracted by too many choices. Another thing to do is to present the available options more visibly to avoid the time-consuming dialogue between client and staff.

The high sell-through factor is due to the fact that nothing is produced that is not sold; only customers dissatisfied with their garments will lower this percentage. The percentage of lost sales will be low because garments may be customised, thereby, increasing a client's likelihood for satisfaction. A traditional retailing company that turns around stock about four times per year has a great deal of money tied up in inventory, negatively affecting its profitability. The stock turnaround for SAMAND' OR can be much higher because only such raw materials as yarn and attachments, but no ready-made garments, have to be kept in inventory at the manufacturing plant. Complete garment technology, with its reduction of manufacturing time by simplifying the processes, makes it possible to produce a garment faster than by using conventional methods. This makes it an important factor for the development of mass customisation concepts of flat-knitted fashion products in the future. Nevertheless, the analysis also showed that there is limited interest in the market for the customisation of coarseknitted garments. Such a lack of interest may be a result of the difficult, time-consuming and personnel-intensive co-design process which, if improved, might encourage the spread of the mass-customising concept. Retailing companies may presently lack sales staff who don't have the experience and skills needed to help customers design their own garments. Store personnel with knowledge in design, pattern construction and with experience in taking body measurements can overcome this problem.

In the future, however, customisation may enable the industry to supply the latest designs while they are still trendy rather than produce merchandise that maybe already out of fashion when it reaches the store. Mass customisation may be one solution to the widespread timeto-market problem, both for knitwear and for like fashion products that lend themselves to a technical solution.

\section{Conclusion}

The first research questions addressed in this study were: "How can complete garment knitting technology by applied in a retail and production concept for customized garments." 
Citation: Peterson J (2016) Customisation and Fashion Logistics Effects of Flat Knitted Fashion Products using Complete Garment Technology SAMAND' OR - A Case Study. J Textile Sci Eng 6: 232. doi:10.4172/2165-8064.1000232

A MC concept can be launched with production facilities off-site, as in the studied SAMAND' OR concept, where the custom-made garment is shipped to the customer by express mail from the production facilities in Wakayama. In this case collaboration between a retailer in central Tokyo and a manufacturer in a distance location seems to work fine. The demand fulfilment time (design time, production time, and transportation time) for a garment from order to customer is 5 to 10 days. The SWOT analysis indicates strengths such as no inventory of ready-made garments, no seasonal sales and a possibility to have the manufacturing process very close to the Point Of Sales, P.O.S. More detailed information shows that the company has no seasonal sales and all products are sold to full price, which affects the sell-through factor positive. For reasons of confidentiality the company does not reveal exact figures in terms of sales figures, sell-through factor and economic results. To prevent the identified weakness with customers queuing in the store, the firm plans to hire more staff during peak hours. To overcome the time consuming co-design process some attempt is under way to test the use of a digital co-design using a computer in the store. The interviews reveal that the company has limited retailing experience and this can be remedied by hiring an experienced parttime consultant in the field.

The second research question: "What impacts can be expected on retail performance effects, such as: sell-through factor, lost sales and stock turn by combining complete garment technology and MC?"

As presented the retail performance factors: sell-through, lost sales and stock turn-over is affected positively in the SAMAND' OR retail concept. This is because the product is sold before it is produced according to the mass customisation idea. The complete garment knitting technology can in the future make the manufacturing time of the product very short, enabling a fast delivery to the customer, maybe in hours. In the future, customisation may enable the industry to supply the latest designs while they are still trendy rather than produce merchandise that maybe already out of fashion when it reaches the shelf in the shop. Rapid production of customised garments fulfils the need to keep time-to-market very short. Short lead times in all processes from the first moment of identified customer demand all the way to a satisfied customer. Mass customisation in combination with complete garment knitting technology may be one solution to the widespread time-to-market problem, both for knitwear and for other fashion products that lend themselves to a technical solution.

\section{Acknowledgements}

The author would like to thank the sales staff and technical experts at SHIMA SEIKI, and the shop personnel at SAMAND'OR at Takashimaya department store, Tokyo for making this study possible. The author would also like to express his appreciation to Japan Society of Promotion of Science (JSPS) for funding this research. JSPS together with Shinshu University in Ueda made my stay in Japan to learning and exciting experience.

\section{References}

1. Fernie J, Azuma N (2004) The changing nature of Japanese fashion: Can quick response improve supplychain efficiency? European Journal of Marketing 38: 790-808

2. Bruce M, Daly L, Towers N (2004) Lean or agile: A solution for supply chain management in the textiles and clothing industry? International Journal of Operations \& Production Management 24: 151-170.

3. Stuart I (1997) Supply-chain strategy: Organizational influence through supplier alliances. British Journal of Management 8: 223-236.

4. Dossenbach $T$ (1999) Basic supply chain management = greater profits. Wood and Wood Products 104: 109-110.

5. Gattorna J (2010) Dynamic Supply Chains: Delivering Value Through People. Financial Times Prentice Hall, Harlow, UK.
6. Hoover W, Eloranta E, Holmström J, Huttunen K (2001) Managing the Demand Supply Chain. John Wiley and Sons, New York.

7. Mattila, H, King R, Ojala N (2002) Retail performance measures for seasonal fashion. Journal of Fashion Marketing and Management. 6: 340-351.

8. Choi W, Powell NB (2006) The Development of Specialized Knitted Structures in the Creation of Resist-Dyed Fabrics and Garments. Journal of the Textile Institute 99: 253-264.

9. Choi W, Powell NB (2005) Three dimensional seamless garment knitting on V-bed flat knitting machines. Journal of Textile and Apparel, Technology and Management. 4: 1-33.

10. Legner M (2003) 3D-products for fashion and technical textile applications from flat knitting machines. Melliand International 9: 238-241.

11. Davis S (1987) Future Perfect. Addison-Wesley, MA, US

12. Pine BJ (1993) Mass Customization: The New Frontier in Business Competition. Harvard Business School Press, Boston.

13. Kay MJ (1993) Making mass customization happen: Lessons for implementation Strategy and Leadership 21: 14-18.

14. Silveira GD, Borenstein D, Fogiliatto FS (2001) Mass customization: Literature review and research Directions. International Journal of Production Economics 72: 1-13.

15. Lee SE, Kunz GI, Fiore AM, Campbell JR (2002) Acceptance of mass customization of apparel: Merchandising issues associated with preference for product, process and place. Clothing and Textiles Research Journal 20: 138146

16. Yin RK (2009) Case Study Research-Design and Methods. 53: Sage Publications, London.

17. Bryman A (2012) Social Research Methods. (4th edn.) Oxford Press, Oxford.

18. Patton MQ (2002) Qualitative Research and Evaluation Methods (3rd edn.). Sage Publications, London.

19. Peterson J, Mattila H (2010) Mass customising of knitted fashion garments: Factory Boutique Shima - A case study. International Journal of Mass Customisation 3: 247-258.

20. Larsson J, Peterson J, Mattila H (2012) The Knit on Demand supply chain Autex Research Journal 12: 67-75.

21. Helms MM, Nixon J (2010) Exploring SWOT analysis - where are we now? A review of academic research from the last decade. Journal of Strategy and Management. 3: 215-251.

22. Kotler P (2000) Marketing Management. Prentice-Hall, Upper Saddle River New Jersey.

23. Spencer DJ (2001) Knitting Technology: A Comprehensive Handbook and Practical Guide. Woodhead Publishing Ltd, Cambridge.

24. Christopher M, Lowson R, Peck, H (2004) Creating agile supply chains in the fashion industry. International Journal of Retail and Distribution Management 32: $367-376$

25. Lowson B, King RE, Hunter A (1999) Quick Response: Managing the Supply Chain to Meet Consumer Demand. Wiley, Chichester, UK.

26. Christopher M, Peck H (1997) (1997) Managing logistics in fashion markets. The International Journal of Logistics Management 8: 63-74.

27. Christopher M (2000) The agile supply chain: Competing in volatile markets Industrial Marketing Management. 29: 37-44.

28. Christopher M, Peck H (1997) Marketing Logistics. Butterworth-Heinemann, Oxford.

29. Mattila H (1999) Merchandising Strategies and Retail Performance for Seasona Fashion Products. Thesis (PhD). Lappeenranta, Finland, Lappeenranta University of Technology.

30. King RE, Hunter NA (1997) Quick Response Beats Importing in Retail Sourcing Analysis. Bobbin 38: 22-30

31. Fiore AM, Lee SE, Kunz G (2001) Relationships between optimum stimulation level and willingness to use mass customisation options. Journal of Fashion Marketing and Management 5: 99-107. 
Citation: Peterson J (2016) Customisation and Fashion Logistics Effects of Flat Knitted Fashion Products using Complete Garment Technology SAMAND' OR - A Case Study. J Textile Sci Eng 6: 232. doi:10.4172/2165-8064.1000232

Page 8 of 8

32. Lampel J, Mintzberg H (1996) Customizing customization. MIT Sloan management Review 38: 21-30.

33. Gilmore JH, Pine BJ (1997) The four faces of mass customization. Harvard Business Review 75: 91-102.

34. Raz S (1993) Flat Knitting. Universal Maschinenfabrik, Westhausen, Germany.

35. Fralix MT (2001) From mass production to mass customization. Journal of Textile and Apparel, Technology and Management 1: 1-7

36. Tseng M, Piller FT (2003) Applying mass customisation to the fashion industry.
In: Tseng M, Piller FT (eds), The Customer Centric Enterprise: Advances in Mass Customization and Personalization. Springer Verlag, Berlin.

37. Lee SE, Chen CC (1999) Mass-customization methodology for an appare industry with a future. Journal of Industrial Technology 16: 1-8.

38. Anderson DM (1997) Agile Product Development for Mass Customization: How to Develop and Deliver Products for Mass Customization. Niche Markets, JIT Build-to-order and Flexible Manufacturing. McGraw-Hill, NewYork.

39. Kincade DH, Regan C, Gibson FY (2007) Concurrent engineering for product development in mass customization for the apparel industry. International Journal of Operations and Production Management 27: 627-649.
Citation: Peterson J (2016) Customisation and Fashion Logistics Effects of Flat Knitted Fashion Products using Complete Garment Technology SAMAND' OR A Case Study. J Textile Sci Eng 6: 232. doi:10.4172/2165-8064.1000232
OMICS International: Publication Benefits \& Features

\section{Unique features:}

- Increased global visibility of articles through worldwide distribution and indexing

Showcasing recent research output in a timely and updated manner

Special issues on the current trends of scientific research

Special features:

700 Open Access Journals

50,000 editorial team

Rapid review process

Quality and quick editorial, review and publication processing

Indexing at PubMed (partial), Scopus, EBSCO, Index Copernicus and Google Scholar etc

Sharing Option: Social Networking Enabled

- Authors, Reviewers and Editors rewarded with online Scientific Credits

- Better discount for your subsequent articles

Submit your manuscript at: http://omicsgroup.info/editorialtracking/textile/ 